\title{
A Modified Wireless Power Transfer System for Medical Implants
}

\author{
Yosra Ben Fadhel ${ }^{1}$, Sana Ktata ${ }^{1}$, Khaled Sedraoui ${ }^{2}{ }^{\circ}$, Salem Rahmani ${ }^{1, *}$ and \\ Kamal Al-Haddad ${ }^{3}$
}

1 Research Laboratory of Biophysics and Medical Technology (BMT) at High Institute of Medical Technologies of the University of Tunis El-Manar, 1002 Tunis, Tunisia; benfadhelyosra@gmail.com (Y.B.F.); sanaktata@yahoo.fr (S.K.)

2 Department of Electrical and Computer Engineering, King Abdulaziz University, Jeddah 21589, Saudi Arabia; Sedraoui@yahoo.com

3 Canada Research Chair in Energy Conversion and Power Electronics CRC-ECPE École de Technologie Supérieure, 1100 Notre-Dame, Montréal, QC H3C 1K3, Canada; kamal@ele.etsmtl.ca

* Correspondence: rsalem02@yahoo.fr; Tel.: +216-98483068

Received: 24 December 2018; Accepted: 24 March 2019; Published: 17 May 2019

\begin{abstract}
Wireless Power Transfer (WPT) is a promising technique, yet still an experimental solution, to replace batteries in existing implants and overcome the related health complications. However, not all techniques are adequate to meet the safety requirements of medical implants for patients. Ensuring a compromise between a small form factor and a high Power Transfer Efficiency (PTE) for transcutaneous applications still remains a challenge. In this work, we have used a resonant inductive coupling for WPT and a coil geometry optimization approach to address constraints related to maintaining a small form factor and the efficiency of power transfer. Thus, we propose a WPT system for medical implants operating at $13.56 \mathrm{MHz}$ using high-efficiency Complementary Metal Oxide-Semiconductor (CMOS) components and an optimized Printed Circuit Coil (PCC). It is divided into two main circuits, a transmitter circuit located outside the human body and a receiver circuit implanted inside the body. The transmitter circuit was designed with an oscillator, driver and a Class-E power amplifier. Experimental results acquired in the air medium show that the proposed system reaches a power transfer efficiency of $75.1 \%$ for $0.5 \mathrm{~cm}$ and reaches $5 \mathrm{~cm}$ as a maximum transfer distance for $10.67 \%$ of the efficiency, all of which holds promise for implementing WPT for medical implants that don't require further medical intervention, and without taking up a lot of space.
\end{abstract}

Keywords: wireless power transfer; active implant; resonant inductive coupling; power transfer efficiency; form factor; coil; DC/AC converter

\section{Introduction}

All over the world particular attention is paid to human health concerns, which represents the first source of joy and well-being. Unfortunately, heart or hearing troubles, vision loss or stomach pathologies in addition to other anomalies may engender in some cases serious issues and in some cases threaten life. All these health problems have highlighted a major and urgent need to find solutions that can not only overcome these complications, but also increase patients' life expectancy, improve their quality life and ensure their comfort and safety. Among the most important medical inventions, implants have realized a very wide scope of biomedical applications and have saved innumerable human lives. Implants are medical devices implanted inside the human body by surgical intervention or by using a natural opening. By the same time, they must be removed only by medical 
intervention [1,2]. Depending on the application, they are either deeply implanted inside the human body or just a few centimeters under the skin. Implants are classified as passive or active by following the rule if they need power or not. Passive ones are used for support or mobility, such as simple screws or artificial valves. By contrast, active implants replace organ functions or treat associated diseases, such as neural or cardiac implants [3-5]. Figure 1 presents examples of current implants, their localization in the human body and their power needs. The power requirements of most active implants range from a few microwatts to a few tens of milliwatts and that usually depends on their specific applications.

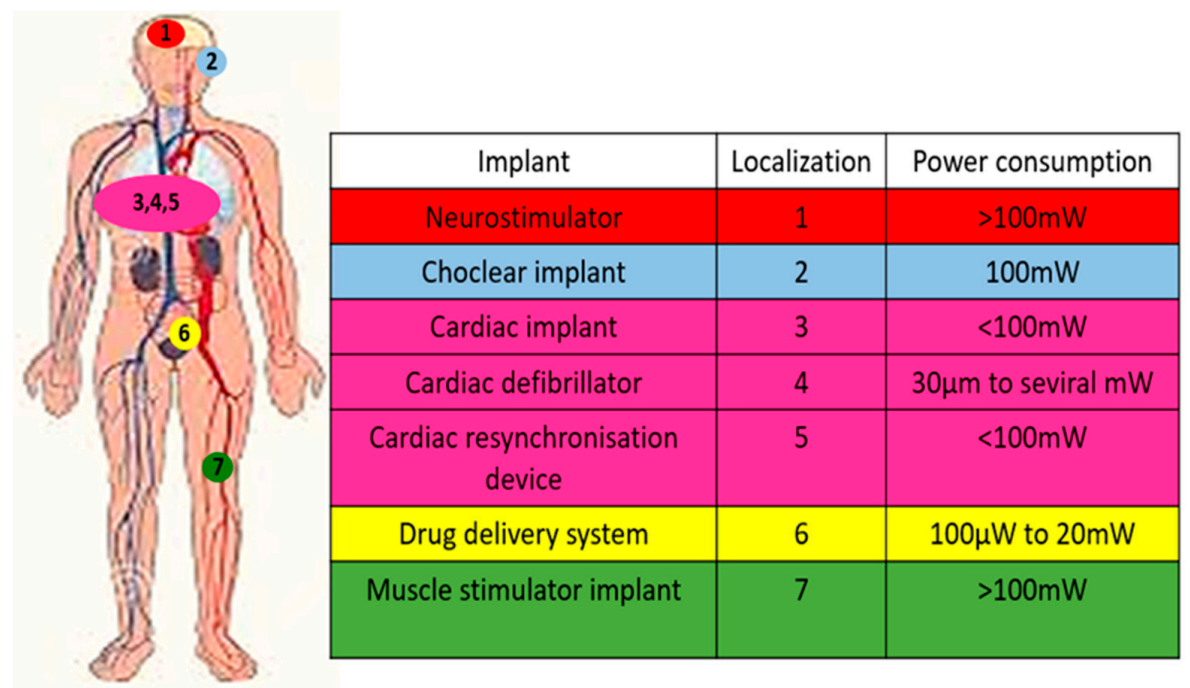

Figure 1. Localization of active implants in the human body and their power consumption.

Implementing electronics in the human body is not entirely new. Hence, for decades deep neural stimulation has already been used to treat various pathologies. However, whenever the energy of the implant is exhausted, the only solution is a second surgical operation to replace the battery. This causes tissue infections and side effects. For this reason, technology is always looking for a solution to make powering implants easier, safer, more efficient, and more comfortable. According to the literature, there are multiple attempts and proposals for powering implants like electric wires, batteries, energy recovery through the human body (piezoelectricity, magnetic induction generators, and electrostatic generators), and energy recovery from the environment (thermal energy, infrared radiation, and wireless power transfer (WPT) $[6,7]$. WPT is the transfer of electrical power from a transmitter point to a consumer power device through the air, vacuum or another environment without the use of wires or any intermediate material. It is a generic term that refers to many different power transfer technologies that use time-varying electromagnetic fields (EM) [8-12]. WPT includes ultrasonic, optical and magnetic waves. However, not all the proposed techniques can satisfy the design requirements of modern implants. Near-field WPT using resonant inductive coupling (RIC) seems the best solution for transcutaneous applications. Table 1 summarizes the significant drawbacks of the main proposed techniques to power-up implants. The RIC phenomenon is to transfer the power between two coils when they are tuned to operate at the same frequency [13,14]. Nevertheless, ensuring a compromise between small form factor, energy transfer efficiency, and patient safety remains a challenge. By inspecting the literature, we can see that many researchers have paid attention to the RIC design in order to improve the PTE. This includes servo loops that can automatically adjust the link parameter variations in order to maintain the resonant state [15], RIC topology modification by using three or four coils may provide a more significant transfer distance [16]. The Q-modulation technique can provide adaptive and efficient inductive power transfer despite the load variations due to the system distance or operation [17]. These solutions deal with the problem of transferring power efficiently. In addition, they increase the implant form factor which is contrary to the objectives of 
modern implant design. In this work, we have used the RIC approach for WPT and a coil geometry optimization approach to address the constraints related to maintaining a small form factor and the efficiency of the power transfer. Thus, we propose a WPT system for medical implants that operates at 13.56 MHz using high-efficiency Complementary Metal Oxide Semiconductor (CMOS) components and an optimized Printed Circuit Coil (PCC). The system implementation has been done in the air medium. It is divided into two main circuits, a transmitter circuit located outside the human body and a receiver circuit implanted inside the body. The transmitter circuit contains an oscillator, driver and a Class-E power amplifier (PA) and it was designed with the software Althuim Designer 2017. The latter allows us to design the circuit with the real package of components. Transmitter $\left(T_{X}\right)$ and receiver $\left(R_{X}\right)$ circular spiral coils have been optimized using the software ADS momentum 2015 by investigating their geometric parameters. All of this holds promise for implementing high efficiency WPT for medical implants that don't require further medical intervention, and without taking up a lot of space.

Table 1. Significant drawbacks of main existing proposed techniques to power-up implants [18].

\begin{tabular}{|c|c|}
\hline Techniques & Drawbacks \\
\hline Electric wires & $\begin{array}{l}\text { Limit patient mobility. } \\
\text { Tissue infection. }\end{array}$ \\
\hline Batteries & $\begin{array}{l}\text { Short lifetime. } \\
\text { Surgical operations necessity. } \\
\text { Big size. } \\
\text { Skin infection. }\end{array}$ \\
\hline $\begin{array}{l}\text { Harvesting energy from the human body } \\
\text { (piezoelectricity, electrostatic generator, } \\
\text { magnetic generator) }\end{array}$ & $\begin{array}{c}\text { Low power. } \\
\text { Energy produced only at organ function (example: piezoelectricity produces } \\
\text { power only at walking). }\end{array}$ \\
\hline \multirow[b]{2}{*}{ Ultrasonic waves } & $\begin{array}{l}\text { They can't penetrate deeply inside the human body due to the high absorption } \\
\text { factor. As a result, they can't deliver reliable power to implants. } \\
\text { Laser beam raises the skin temperature. }\end{array}$ \\
\hline & $\begin{array}{c}\text { Can only send data or energy over a short distance due to the massive power } \\
\text { absorption loss at high frequencies. } \\
\text { Power reception shows significant vulnerability to misalignment between } \\
\text { transmitter and receiver circuits. }\end{array}$ \\
\hline Radio frequency & The high-power absorption heat surrounding tissues. \\
\hline
\end{tabular}

The reminder of this paper is as follows: Section 2 presents the used method and materials to design the proposed system, namely a description of the equivalent electrical circuit of our RIC WPT system in Section 2.1, the choice of high efficiency components for the DC/AC converter in Section 2.2 and optimization of the coils form factor and efficiency in Section 2.3. Section 3 describes the testing methodology and the experimental results. Section 4 discusses the measured results, provides a comparison with the literature methods and mentions the perspectives that open up following this work.

\section{Design of the Proposed System}

WPT techniques are divided into two types, namely, far field and near-field WPT. The far field type includes lasers and microwaves that transfer a high amount of power between the transmitter and the receiver circuits. However, this category isn't suitable for powering implants because it can cause critical tissue heating. Near field techniques are ideal for short and midrange distances and rely on the shape and the size of the transmitter and receiver coils. Near-field techniques include capacitive, inductive, and RIC methods. In this work, we propose to apply the RIC technique. In fact, several reasons justify our choice. Firstly, this technique has a simple implementation which responds to the design requirements of modern implants. Secondly, it ensures high power transfer compared with the inductive and the capacitive coupling [19]. Finally, it is safe and biocompatible with the human body. According to the International Commission for Non-ionizing Radiation Protection (ICNIRP) [20] and the Institute of Electrical and Electronics Engineers (IEEE) [21] for safety levels to radio frequency 
(RF) and electromagnetic field (EMF) exposures, human exposure to magnetic, electric and EM fields can cause the body temperature to increase, heat body tissues, stimulate muscles and nerve tissues, but there is no formal evidence that they will cause cancer.

In a near-field RIC system, the current flowing in the primary coil generates a magnetic flux through the secondary one. The magnetic field lines shared between them induce an alternative voltage in the receiver circuit, which is addressed to satisfy the power needs of the implant. To create the RIC phenomenon and to supply the implant's components, other circuits are required in the complete system. In addition, to generate an alternating current with a precise amplitude, shape, and frequency, an oscillator and a power amplifier are essential. Figure 2 illustrates the schematic diagram of the proposed system to power-up a medical implant. During the system design, we have first put an oscillator that generates a sinusoidal signal from a DC power supply, followed by a driver that allows the class E power amplifier transistor to switch on and off. The Class-E power amplifier is supposed to provide the maximum power to the primary coil when the primary resonance circuit is tuned at the switching frequency (13.56 MHz). The received power in the implanted coil is an AC waveform. What follows is a more in depth description of the proposed components and the justifications for choosing them based on efficiency and small form factor considerations.

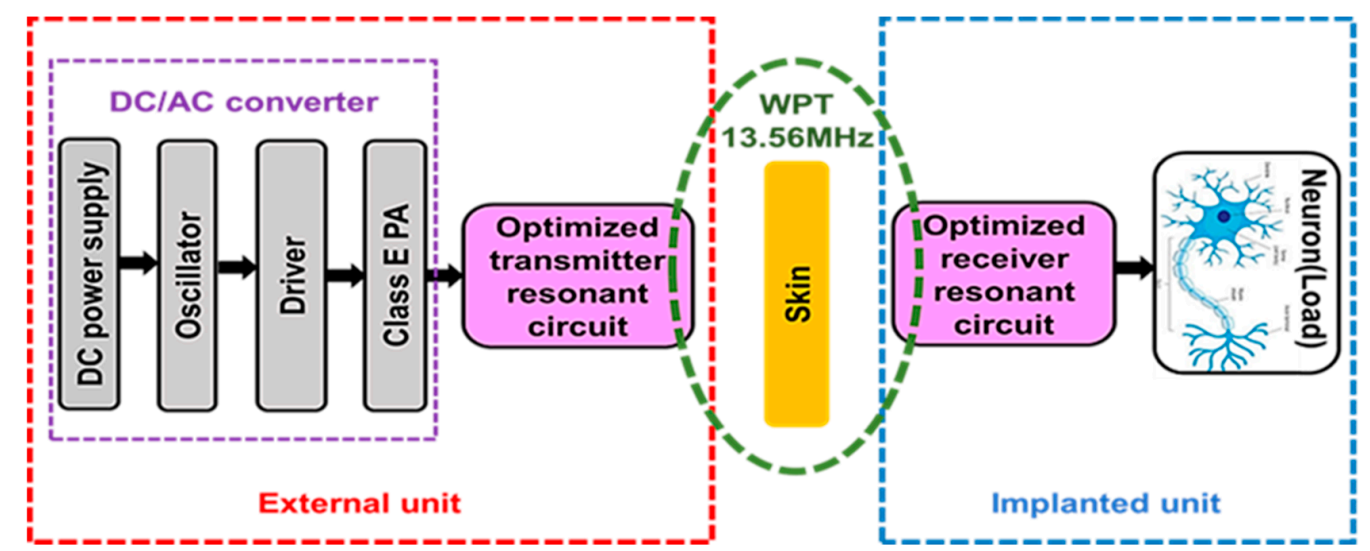

Figure 2. Schematic diagram of the proposed system.

\subsection{Equivalent Electrical Circuit of the Proposed RIC WPT System}

Actually, inductive coupling links are considered the most attractive technology for transcutaneous applications. WPT in bio-device systems is ensured between two coils (see Figure 3). The transmitter coil $\left(T_{X}\right)$ is located outside the human body and the receiver coil $\left(R_{X}\right)$ is inside the body.

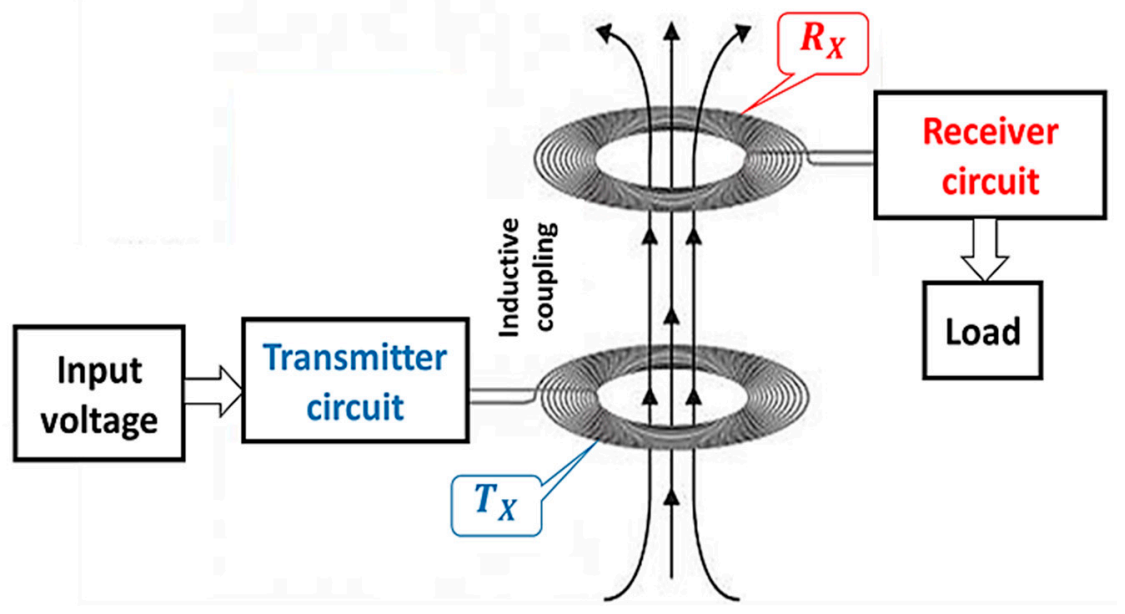

Figure 3. Inductive coupling between two circular coils. 
For transcutaneous applications, high-coupling efficiency is desirable as it translates into lower power loss in the form of heat dissipation. The first step towards increasing PTE is the use of resonant tuning as first proposed by Tesla [14]. The resonant inductive coupling technique allows power transfer at a midrange between two coils when they are in a resonance state [11]. The equivalent electrical circuit of the RIC between two coils has four possible resonant topologies that are: series-parallel (SP), parallel-series (PS), series-series (SS) and parallel-parallel (PP) [22,23]. For the proposed system, we have selected the SP topology (see Figure 4) for the three main reasons listed below:

(1) According to [24-28] the SP topology ensures greater power transfer efficiency than the other topologies in WPT applications.

(2) The serial topology in the transmitter circuit is appropriate with the Class-E power amplifier topology since the chosen Class-E power amplifier has a tuning capacitor in parallel and a tuning capacitor in series $[29,30]$ reducing the complexity of the system.

(3) In the case where a rectifier will be added to the proposed system, the parallel topology is the most adequate. As the authors in the review paper [31] have explained, the resonance at the receiver circuit can be tuned in series or in parallel. Both parallel and serial topologies deliver the same power to the implant. However, the resonant serial topology does this by using a high voltage and a low current. Since rectifiers work better at large voltages and low currents, this makes the parallel topology the leading choice in biomedical implants.

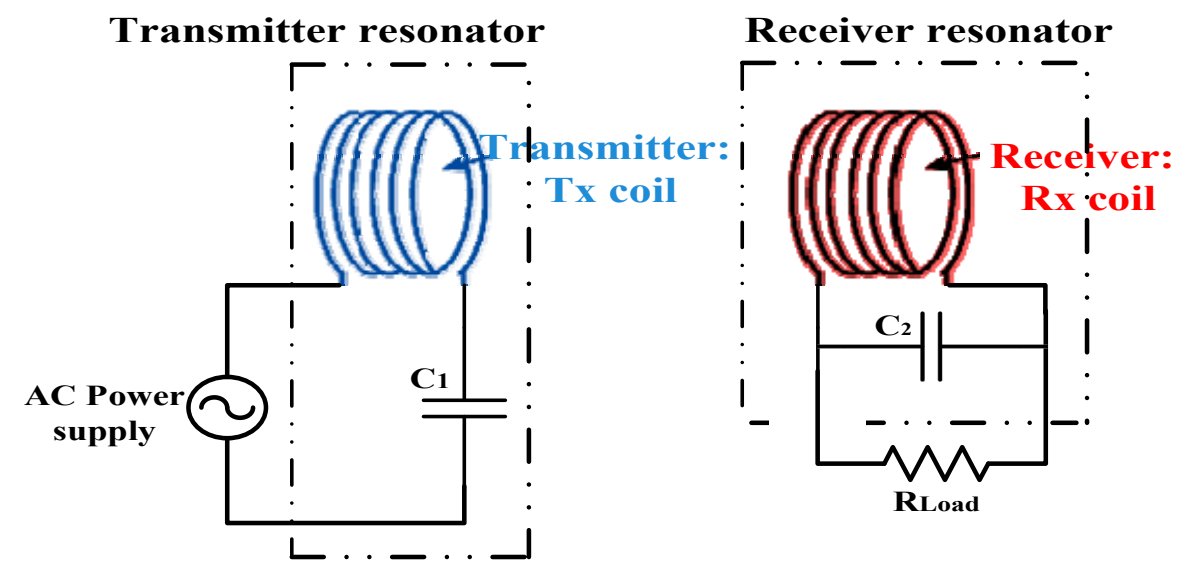

(a)

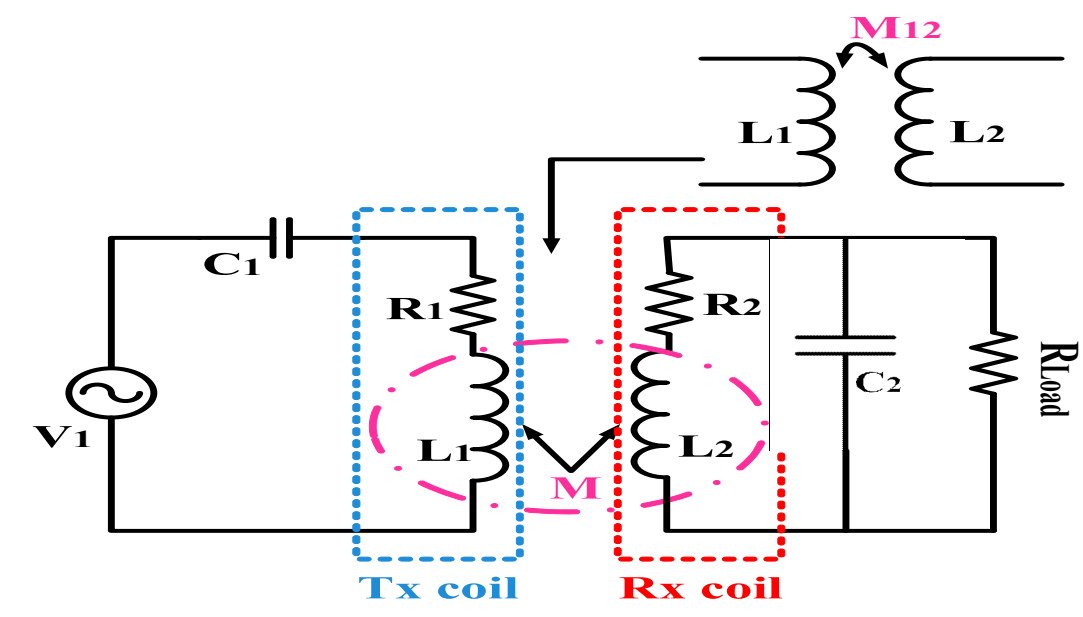

(b)

Figure 4. The serial-parallel (SP) resonant topology used in the proposed system. (a) Simplified model; (b) electrical model. 
Figure 4a shows that the transmitter coil $\left(T_{X}\right)$ is connected to an AC source supply and the load is connected to the receiver coil $\left(R_{X}\right)$. Both coils and capacitors in the two circuits form the transmitter and the receiver resonators of a series-parallel topology (SP). RIC coupling takes place when the two circuits are tuned to operate at the same frequency $f_{0}$ (Equation (1)). At resonance, the impedance and the current of an RLC-circuit are at their extrema. As a result, the voltages at capacitors and at coil terminals are also at their extrema. In addition, the PTE reaches its maximum value $\left(P T E_{\max }\right)$. According to Figure $4 \mathrm{~b}, L_{1}$ in series with $R_{1}$ and $L_{2}$ in series with $R_{2}$ form the equivalent electrical model of $T_{X}$ and $R_{X}$, respectively. In addition, capacitors $C_{1}$ in series with $T_{X}$ and $C_{2}$ in parallel with $R_{X}$ coils, form the transmitter and the receiver resonators. They are tuned at the desired frequency in the aim to ensure an optimum WPT circuit [10]. WPT between the two coils is ensured by the mutual inductance, M [14].

$$
\mathrm{f}_{0}=\frac{1}{2 \pi \sqrt{\mathrm{L}_{1} \mathrm{C}_{1}}}=\frac{1}{2 \pi \sqrt{\mathrm{L}_{2} \mathrm{C}_{2}}}
$$

The mutual inductanceHaut du formulaireBas du formulaire $M$ existing between two coils is in terms of the self-inductance of each coil, is expressed as:

$$
M=\sqrt{L_{1} L_{2}}
$$

where $L_{1}$ and $L_{2}$ are as follows:

$$
\begin{aligned}
& L_{1}=\frac{\mu_{0} \mu_{r} N_{1}^{2} A}{l} \\
& L_{2}=\frac{\mu_{0} \mu_{r} N_{2}^{2} A}{l}
\end{aligned}
$$

with:

$L_{1}$ and $L_{2}$ in Henry,

$\mu_{0}$ : the permeability of free space $\left(4, \pi, 10^{-7}\right)$,

$N$ : turns number,

$A$ : The inner core area $\left(\pi \cdot \mathrm{r}^{2}\right)$ in $\mathrm{m}^{2}$,

$l$ : the length of coil in meters,

$\mu_{r}$ : the relative permeability of the iron core.

It should be noted that $M$ can be also expressed as a function of the coupling coefficient, $K$. The latter is the fraction of the total possible flux linkage between coils [12]. The mathematical expression of $K$ is:

$$
K=\frac{M}{\sqrt{L_{1} L_{2}}}
$$

In inductive coupling, the transmitter and the receiver coils are loosely coupled for the reason that their separation is comparable with the receiver coil dimensions. Under such conditions, the system presents a low efficiency. From (2) to (5), we can infer that improving the system efficiency is possible by increasing the magnetic strength (by increasing the current), the rate of the magnetic field change (by increasing the frequency), and the flux linkage between the two coils (by reducing the misalignment and distance). The reflected impedance $\left(Z_{R}\right)$ from the secondary circuit to the primary circuit is expressed as follows [22]:

$$
Z_{R}=\frac{-j w M I_{2}}{I_{1}}=\frac{w^{2} M^{2}}{Z_{2}}
$$

where $I_{1}$ and $I_{2}$ are the current in $T_{X}$ and $R_{X}$, respectively, and $w=2 \pi f$ is the angular frequency measured in radian/sec. The impedance of a parallel topology in the secondary side, $Z_{2}$ is:

$$
Z_{2}=R_{2}+j w L_{2}+\frac{1}{j w C_{2}+\frac{1}{R_{\text {Load }}}}
$$


According to (6), for the parallel-secondary circuit, the reflected impedance is expressed as the reflected resistance and the reactance, at the resonance $w_{0}=\frac{1}{\sqrt{L_{2} C_{2}}}$, as follows:

$$
\text { Parallel-secondary circuit }\left\{\begin{array}{l}
R_{e}\left(Z_{R}\right)=\frac{M^{2}\left(C_{2} R_{\text {Load }}^{2} R_{2}+L_{2} R_{\text {Load }}+R_{2} L_{2}\right) C_{2} w_{0}^{2}}{2 R_{2} R_{\text {Load }} L_{2} C_{2}+R_{2}^{2} L_{2} C_{2}+R_{2}^{2} C_{2}^{2} R_{\text {Load }}^{2}+L_{2}^{2}} \\
I_{m}\left(Z_{R}\right)=\frac{M^{2} L_{2} w_{0}}{2 R_{2} R_{\text {Load }} L_{2} C_{2}+R_{2}^{2} L_{2} C_{2}+R_{2}^{2} C_{2}^{2} R_{\text {Load }}^{2}+L_{2}^{2}}
\end{array}\right.
$$

In the case where $R_{2}=0$, Equation (8) is expressed as follows [22]:

$$
\text { Parallel-secondary circuit }\left\{\begin{array}{l}
R_{e}\left(Z_{R}\right)=\frac{R_{\text {Load }} M^{2}}{L_{2}^{2}} \\
I_{m}\left(Z_{R}\right)=-\frac{w_{0} M^{2}}{L_{2}}
\end{array}\right.
$$

The PTE is determined as follows:

$$
\mathrm{PTE}=\frac{P_{2}}{P_{1}}
$$

With $P_{1}$ is the power in the transmitter circuit, and $P_{2}$ is the transferred power from the transmitter circuit to the receiver circuit. Table 2 lists the parameters of the RIC circuit proposed in this work.

Table 2. Parameters of the RIC circuit.

\begin{tabular}{cc}
\hline Parameter & Value \\
\hline$L_{1}$ & $5.48 \mathrm{uH}$ \\
$C_{1}$ & $28 \mathrm{pF}$ \\
$L_{2}$ & $1 \mathrm{uH}$ \\
$C_{2}$ & $137.75 \mathrm{pF}$ \\
\hline
\end{tabular}

The equivalent impedance of the secondary circuit is expressed as:

$$
Z_{\text {eq }}=\frac{w^{2} M^{2}\left(R_{\text {Load }}+\sqrt{R_{\text {Load }}^{2}-4 w^{2} L_{2}^{2}}\right)}{2 w^{2} L_{2}^{2}+R_{2} \cdot R_{\text {Load }}+R_{L 2} \sqrt{R_{\text {Load }}^{2}-4 w^{2} L_{2}^{2}}}
$$

To make sure that (11) is true, the following condition should be satisfied:

$$
R_{\text {Load }}^{2}-4 w^{2} L_{2}^{2}>0 \Rightarrow R_{\text {Load }}>2 w L_{2}
$$

The used load $R_{\text {Load }}$ satisfies the requirement:

$$
R_{\text {Load }}=300 \Omega>170.4 \Omega
$$

\subsection{DC/AC Converter - Choices of Components and Justification}

In order to power-up the transmitter coil, the system must generate an $\mathrm{AC}$ voltage at a precise amplitude and frequency. For that, an oscillator and a power amplifier are indispensable. For the oscillator, our choice is a SiT8008B and for the amplifier, we have chosen a Class-E power amplifier.

\subsubsection{Oscillator SiT8008B}

An oscillator is an electronic circuit or component that generates a single frequency periodic output signal from a DC voltage source. This signal goes from a low level to a high level. It remains for a short time in the low state then goes back to the high state, and the cycle continues in this way without stopping, as long as the required conditions for the oscillation to occur are met. The quality of the signal is represented by the harmonic distortion rate (THD). It is defined as the ratio between the overall root mean square (RMS) value of the harmonics and the (RMS) value of the fundamental component. 
In addition, the fundamental frequency has a range of variation $\left[f_{0}-\Delta f, f_{0}+\Delta f\right]$. The frequency stability ratio $\sigma$ reflects the ability of the oscillator to produce a stable frequency. It is often measured in parts per million "ppm" at a given temperature usually chosen at $25^{\circ} \mathrm{C}$ :

$$
\sigma_{p m m}=10^{6} \frac{\Delta f}{f_{0}}
$$

In our case, the SiT8008B produces an AC signal in the chosen frequency 13.56 MHz. Its main advantage is its simplicity. This type of oscillator is exact and stable in frequency ( $\pm 50 \mathrm{ppm})$ and its energy consumption is low. In addition, it is only weakly influenced by temperature variations.

\subsubsection{The Operating Frequency: $13.56 \mathrm{MHz}$}

The allowed frequency (13.56 MHz) is not arbitrary; contrariwise, it satisfies the industrial, scientific and medical (ISM) bands. Table 3 presents the common distribution band allocated for all (ISM) applications.

Table 3. Distribution ISM bands.

\begin{tabular}{cccc}
\hline Frequency Bands & $\begin{array}{c}\text { Low Frequencies } \\
\text { (LF) }\end{array}$ & High Frequencies (HF) & $\begin{array}{c}\text { Ultra-High Frequency } \\
\text { (UHF) }\end{array}$ \\
\hline \multirow{2}{*}{ Values } & 100 to $150 \mathrm{KHz}$ & $\begin{array}{c}6.78 \mathrm{MHz}, 13.56 \mathrm{MHz}, 27 \mathrm{MHz}, 125 \\
\mathrm{MHz} \text { and } 40.68 \mathrm{MHz}\end{array}$ & $\begin{array}{c}433.92 \mathrm{MHz}, 869 \mathrm{MHz} \\
\text { and } 2.4 \mathrm{GHz}\end{array}$ \\
\hline
\end{tabular}

According to the standard established by the International Telecommunication Union (ITU), the permitted currents at $100-135 \mathrm{KHz}, 6.78 \mathrm{MHz}$ and $13.56 \mathrm{MHz}$ are respectively $66 \mathrm{~dB} \mu \mathrm{A} / \mathrm{m}$, $42 \mathrm{~dB} \mu \mathrm{A} / \mathrm{m}$ and $42 \mathrm{~dB} \mu \mathrm{A} / \mathrm{m}$. The intensity allowed at a low frequency is higher than the one allowed to the HF band. In addition, the heating effect of the tissues in this band is negligible or even non-existent. Actually, $13.56 \mathrm{MHz}$ is considered the most appropriate frequency in research works. In fact, it ensures a compromise between the authorized magnetic field strength, the transmission range and the biocompatibility $[20,21]$.

\subsubsection{Class-E Power Amplifier}

Usually, a system for transcutaneous applications begins with a power amplifier (PA), which supplies the power to the transmitter coil at a particular frequency and a voltage amplitude. Higher transmission frequencies place a specific focus on utilizing power amplifiers which operate efficiently at these levels. Switched power amplifiers are a popular choice to drive inductive power coupling for implants due to their ability to minimize losses at higher frequencies. Table 4 presents their main characteristics [29]. During the WPT system design for implants, several challenges should be realized. Among them, we notice the achieving of a high PTE and the reducing of the system dimension. These objectives make the Class-E power amplifier very suitable for implants since it has a $100 \%$ of theoretical efficiency. In addition, it can operate at a frequency range from $3 \mathrm{MHz}$ to $10 \mathrm{GHz}$ [17]. Moreover, it contains only one active device that is a transistor. This component drives a series resonant circuit (see Figure 5).

Table 4. Switched power amplifiers.

\begin{tabular}{cl}
\hline Switcher Power Amplifiers & \multicolumn{1}{c}{ Characteristics } \\
\hline Class D & $\begin{array}{l}\text { The theoretical efficiency of } 100 \% \text {. The parasitic capacitance } C_{s S} \text { causes an } \\
\text { energy dissipation during switching cycles. }\end{array}$ \\
Class-F & $\begin{array}{l}\text { Useable for radio frequencies (from } 9 \mathrm{kHz} \text { to } 300 \mathrm{Mhz} \text { ). Has a unit efficiency. } \\
\text { Class-E }\end{array}$ \\
& The theoretical efficiency of $100 \%$. High-frequency applications, from \\
& $3 \mathrm{MHz}$ until 10 GHz. \\
\hline
\end{tabular}




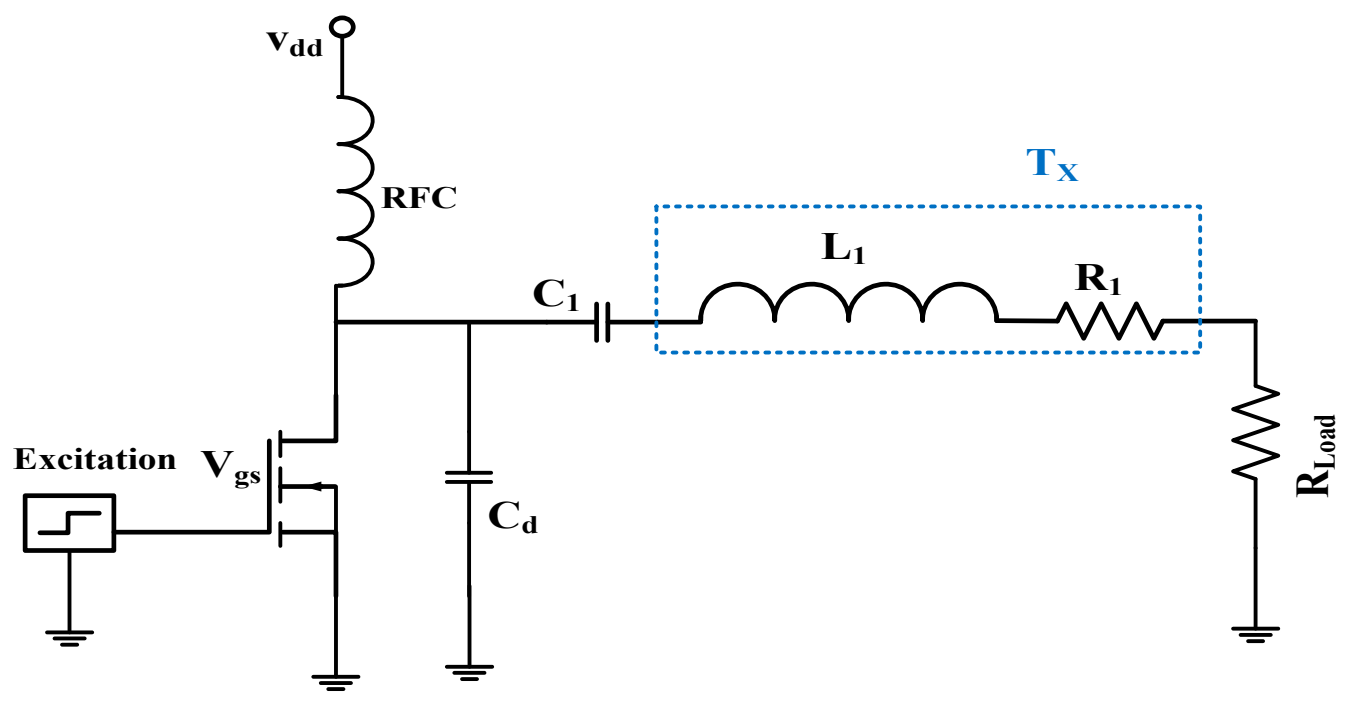

Figure 5. Class-E power amplifier.

\subsubsection{Class-E Power Amplifier Transistor DMG230UK-7}

During system design, our aim is to reduce the power losses as much as possible, which makes the "Enhancement-mode" N-junction type transistor an optimal choice. For the proposed system, we have used the DMG230UK-7 that is a high-speed N-junction metal oxide semiconductor field transistor (MOSFET). From its data sheet, $R d s_{o n}=13 \mathrm{~m} \Omega$, which is small, which supports our choice. Note also that the $C_{i s s}$ input capacitance value is high. However, that is inevitable if we want to get a low resistance $R d s_{o n}$, this large capacity must have a large current to ensure a short switching time. Only an oscillator couldn't provide a sufficient amount of the current at a high frequency of $13.56 \mathrm{MHz}$. Therefore, adding a preamplifier "driver" is essential. It will be configured as a voltage follower at the oscillator output.

\subsubsection{Driver LM5134}

The current through a capacitor is as follows:

$$
I=\frac{C_{i s s} \cdot v_{g s}}{t_{o n}}
$$

where $t_{o n}$ is the time required to recharge the gate capacity of the transistor fully. In general, it takes a total time equal to $4 \tau$ to recharge completely the capacitor:

$$
t_{\text {on }}=4 \tau\left(R_{d}+R_{g}\right) C_{i s s}
$$

$R_{d}$ is the driver output resistor and $R_{g}$ is the internal gate resistance. According to the data sheets $R_{d}=0.2 \Omega$ and $R_{g}=1.7 \Omega$. If the transition time $T_{o n}$ is chosen to correspond to $2 \%$ of the control signal period $(\mathrm{f}=13.56 \mathrm{MHz})$, and considering that the target gate voltage $\left(v_{g s}\right)$ is $3.3 \mathrm{~V}$, we obtain:

$$
\begin{gathered}
T_{\text {on }}=0.02 \mathrm{~T}=1.475 \mathrm{~ns} \\
I=\frac{400 p F .3 .3 \mathrm{~V}}{1.474 n \mathrm{~s}}=897.95 \mathrm{~mA}
\end{gathered}
$$

Then, our choice is the LM5134 Texas Instrument driver for a peak output current value of 7.6 A in the sink and 4.4 A source and a driver output resistance $R_{d}=0.2 \Omega$, which is appropriate with the MOSFET used. Therefore, both the SiT8008 and the LM5134 are good choices to ensure the proper operation of the Class E power amplifier. To power-up SiT8008B oscillator, we have chosen a MCP1501 $3.3 \mathrm{~V} / \mathrm{DC}$ power supply. 


\subsubsection{Ceramic Capacitors}

In order to have a stable transmitter in frequency and temperature, we propose the use of multilayer ceramic capacitors. Hence, they have high stability, a very low-temperature coefficient and a considerable quality factor. All these characteristics help to reduce power losses.

\subsection{Transmitter and Receiver Coils Design Optimization}

In this section, we will look at the influence of different parameters of the circular coils and the steps of our methodology to find an optimal balance between the coil size or form factor and the coil efficiency. Figure 6 presents the parameters of a circular coil and Equation (18) determines the number of turn corresponding to each inductance value [18]. In the following, we deal with the coupled printed spiral coils (PSC) geometry optimization of the two inductance values $\left(L_{1}\right.$ and $\left.L_{2}\right)$ using the advanced design system (ADS) software.

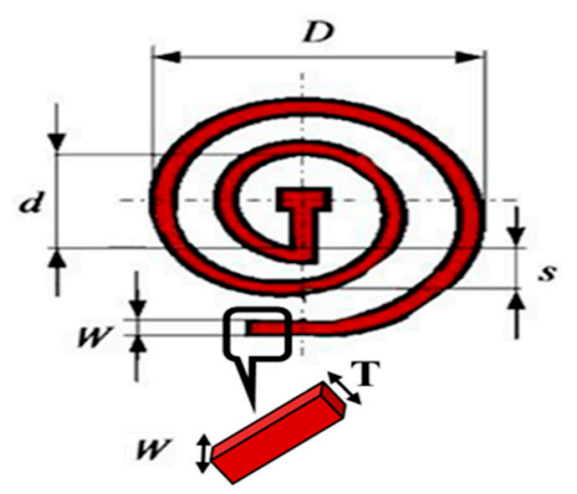

Figure 6. Geometry of a circular spiral coil.

with:

$D$ : coil outer diameter $(\mathrm{mm})$,

$d$ : coil inner diameter $(\mathrm{mm})$,

$s$ : conductor spacing $(\mathrm{mm})$,

W: conductor width $(\mathrm{mm})$,

$T$ : conductor thickness (mm).

$$
L=\frac{u_{0} N^{2} D_{a v g} C_{1}}{2}\left(\ln \left(\frac{C_{2}}{\varphi}\right)+c_{3} \varphi+c_{4} \varphi^{2}\right)
$$

with:

$L:$ inductance in Henry,

$u_{0}$ : is the absolute permeability of the free space,

$D$ : coil outer diameter $(\mathrm{m})$,

$d$ : coil inner diameter $(\mathrm{d})$,

$N$ : Turns number,

$D_{\text {avg: }}$ : coil average diameter,

C: for a circular coil are as follows: $\mathrm{C} 1=1, \mathrm{C} 2=2.46, \mathrm{C} 3=0$ and $\mathrm{C} 4=0.20$,

$\varphi$ : filling factor,

$D_{\text {avg }}=(D+d) / 2, \varphi=(D-d) /(D+d)$.

Iterative Design Procedure for the Coil Optimization

With the aim of optimizing the size and the quality factor of the two coils, we have followed an iterative procedure that consists of four steps as presented in Figure 7. 


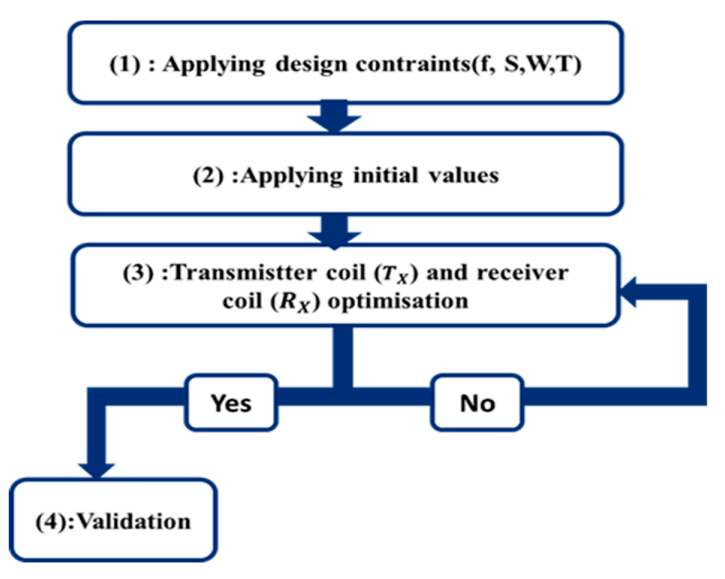

Figure 7. Followed steps to optimize the two coils.

Each step is explained as follows:

- Step (1): applying design constraints and step (2): applying initial values

To design the coils we have used the copper as a conductor and Flame Resistant 4 (FR4) as a dielectric. Table 5 presents their physical characteristics that we must respect during the system simulation. The first step in the optimization of coils is to apply the design parameters limited by the implant and the fabrication technology. For our case, these parameters are listed in Table 6 . Figure 8 presents a $3 \mathrm{D}$ visualization of $T_{X}$ in the ADS momentum software.

Table 5. FR4 and conductor: copper parameters.

\begin{tabular}{cc}
\hline Parameter & value \\
\hline Copper resistivity & $1.68 \times 10^{-8} \Omega \mathrm{m}$ \\
Copper conductivity & $5.96 \times 10^{7} \Omega^{-1} \mathrm{~m}^{-1}$ \\
Relative FR4 constant $\left(E_{r}\right)$ & 4.15 until $500 \mathrm{MHz}$ \\
FR4 loss tangent $($ TanD) & 0.02 until $500 \mathrm{MHz}$ \\
\hline
\end{tabular}

Table 6. parameters limited by the implant and the fabrication technology.

\begin{tabular}{ccc}
\hline Parameters & Unit & Value \\
\hline Frequency & $(\mathrm{MHz})$ & 13.56 \\
Inductor $\left(L_{1}\right)$ of the transmitter coil $T_{X}$ & $(\mathrm{H})$ & $5.48 \times 10^{-6}$ \\
Inductor $\left(L_{2}\right)$ of the receiver coil $R_{X}$ & $(\mathrm{H})$ & $10^{-6}$ \\
Copper thickness & $(\mathrm{mm})$ & $\geq 0.0445$ \\
W:Conductor width & $(\mathrm{mm})$ & $\geq 0.203$ \\
S:Conductor spacing & $(\mathrm{mm})$ & $\geq 0.203$ \\
Via diameter & $(\mathrm{mm})$ & 0.6 \\
FR4 thickness & $(\mathrm{mm})$ & 1.4986 \\
\hline
\end{tabular}

Figure 8 presents a 3D visualization of $T_{X}$ in the ADS momentum software.

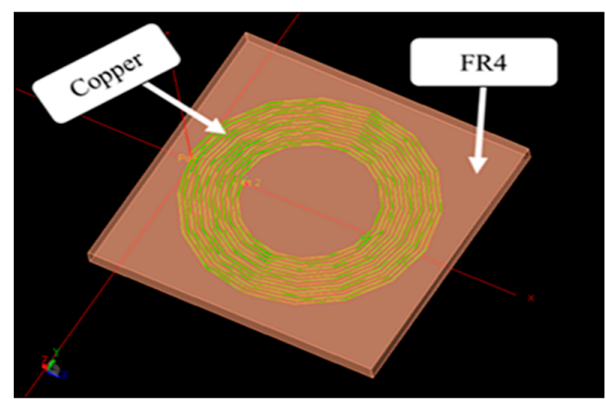

Figure 8. 3 Visualization of $T_{X}$ in ADS momentum. 
- Step (2): Transmitter coil $\left(T_{X}\right)$ and receiver coil $\left(R_{X}\right)$ optimization

To get the desired inductance values $\left(L_{1}\right.$ and $\left.L_{2}\right)$ of the two coils, several coil geometries are possible. Nevertheless, not all of them give coils with a high-quality factor $\left(Q_{L}\right)$. Coil quality factor $\left(Q_{L}\right)$ is an important parameter in improving the inductive coupling of a WPT system. Improving this parameter leads to minimize the electromagnetic heating of the tissue, the interference with other devices, and imperatively the safety of the patient. The quality factor of an unloaded (PSC) can be expressed as [32]:

$$
Q_{L}=\frac{w_{n} L_{n}}{R_{n}}
$$

with $w_{n}$ is the angular frequency, $L_{n}$ is the inductor of the coil and $R_{n}$ is the parasitic resistance. $Q$ is related to the parasitic resistance and the capacitance of the inductor. Taking account, the skin effect, the total parasitic resistance can be calculated as follows:

$$
R_{n}=R_{d c} \frac{t_{c}}{\delta\left(1-e^{-\frac{t_{c}}{\delta}}\right)}
$$

with $\delta$ being the skin metal depth and $R_{d c}$ the DC resistance, expressed as follows:

$$
\begin{gathered}
R_{d c}=\rho_{c} \frac{l_{c}}{W \cdot t_{c}} \\
\delta=\sqrt{\frac{\rho_{c}}{\pi \cdot \mu \cdot f}} ; \mu=\mu_{r} \cdot \mu_{0}
\end{gathered}
$$

where $l_{c}$ is the total length of the conductor, $t_{c}$ is the conductor thickness, $W$ is the conductor width, $\rho_{c}$ is the metal resistivity, $\mu$ is the permeability (constant), and $\mu_{r}$ is the relative permeability of the conductor.

To optimize the transmitter and the receiver coil, we have done five tests for each one following the same steps. Figure 9 illustrates the circuit block diagram coil form factor and the efficiency optimization using ADS. Firstly, we have used the "S-PARAMETRS" bloc in which we have fixed the desired frequency $(13.56 \mathrm{MHz})$ to simulate the coil. Secondly, in "M Sub" bloc we have inserted the substrate thickness $(\mathrm{H})$, the relative dielectric constant $\left(E_{r}\right)$, the relative permeability (Mur), the conductor thickness $(\mathrm{T})$, the conductor conductivity (Cond), and the dielectric loss tangent (TanD), respectively (see Tables 5 and 6). Thirdly, we have used a part impedance value equal to $50 \Omega$. Finally, we have still varying the coil number of turns $(\mathrm{N})$, the conductor spacing $(\mathrm{S})$, the conductor width $(\mathrm{W})$ and the inner radius ( $\mathrm{Ri})$; using an optimization function offered by ADS, accompanying by the calculation of the parasitic resistance (R_Coil), the inductance value of the coil (L_Coil) and the equivalent impedance (ZS_Coil) (see Figures 9 and 10). These parameters are determined in ADS momentum using the following equations (written in the style required by ADS):

$$
\begin{aligned}
\text { R_Coil } & =\operatorname{real}(\text { Zin }(S 11, \text { PortZ1 }) \\
\text { ZS_Coil } & =\operatorname{imag}(\text { Zin }(S 11, \text { PortZ1 }) \\
\text { L_Coil } & =(\text { ZS_Coil }) /\left(2^{*} \text { pi }^{*} \text { freq }\right)
\end{aligned}
$$




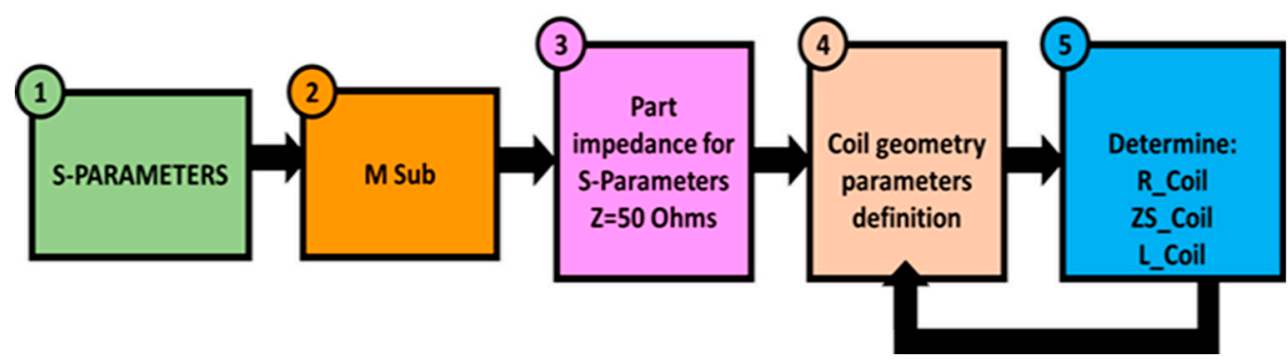

Figure 9. Block diagram of the coil form factor and the efficiency optimization using ADS.

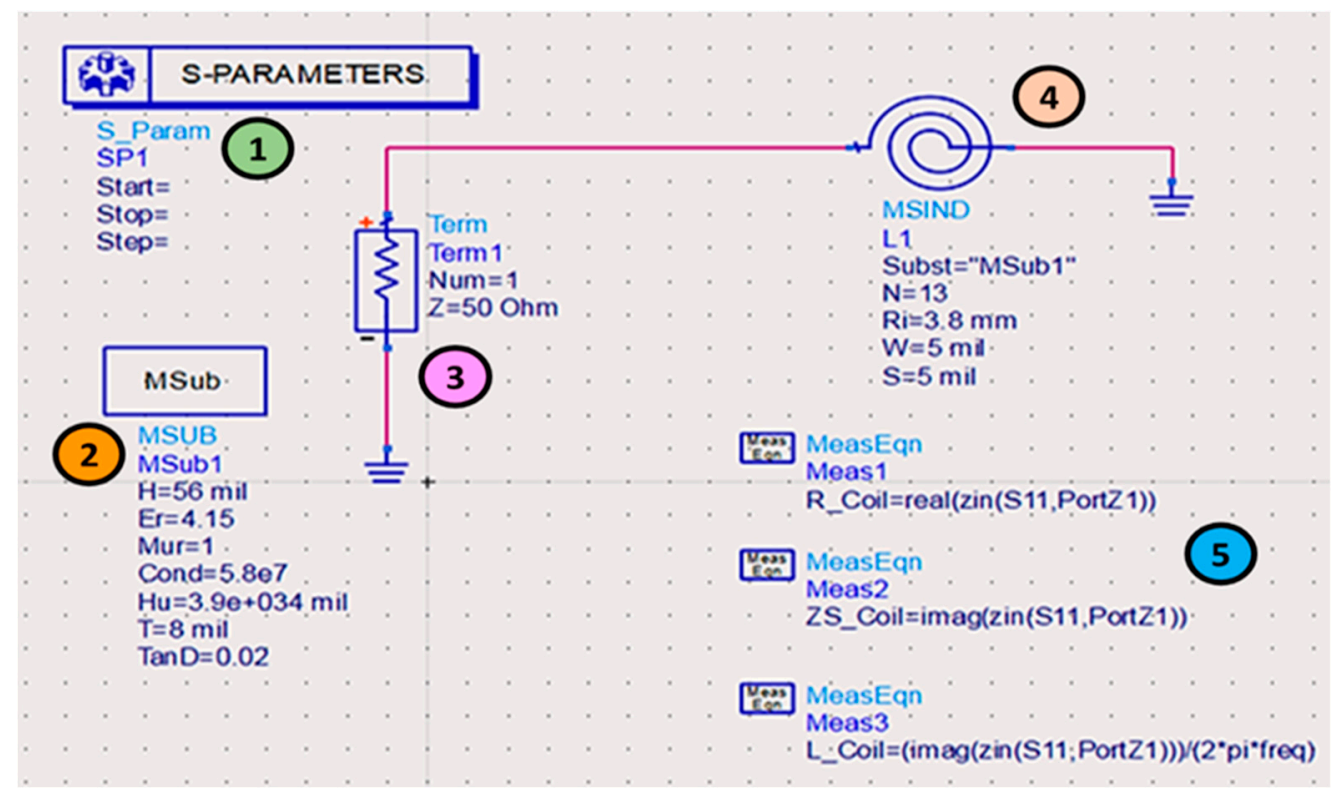

Figure 10. Coil form factor and efficiency optimization using ADS.

ADS allows to specify the operating frequency during the optimization procedure. Figure 11 illustrates an example of the simulation result giving the receiver coil in ADS momentum at $13.56 \mathrm{MHz}$.

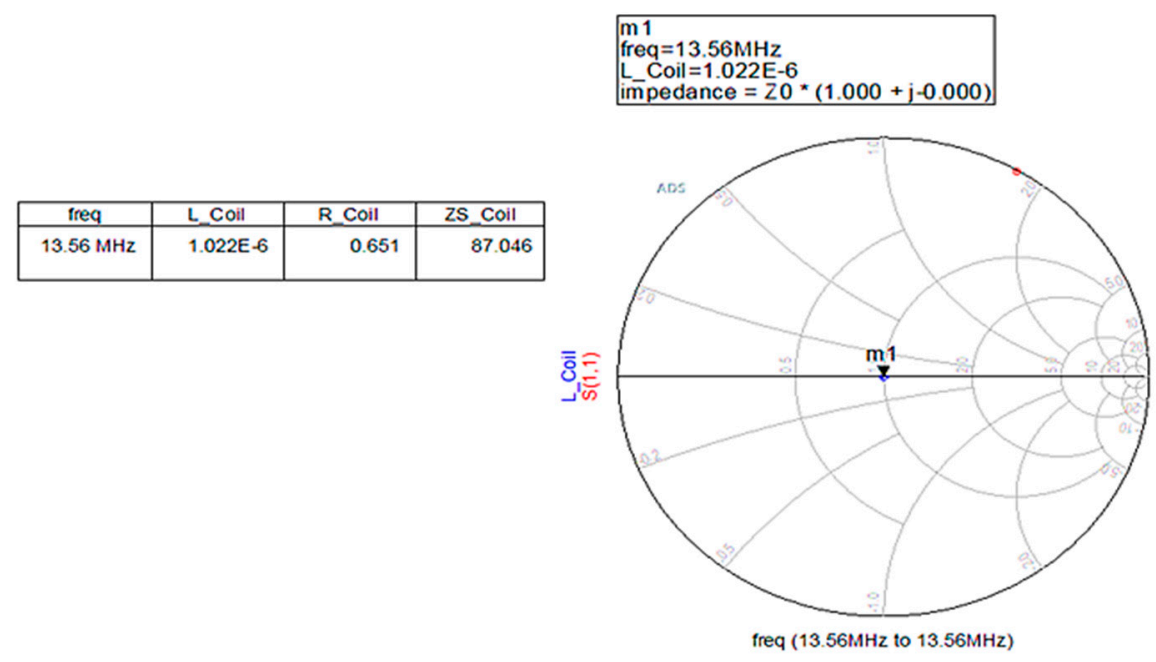

Figure 11. Simulation result of the receiver coil optimization in ADS momentum.

- Step (3): Validation

Before proceeding to the practical validation of the coils, we have compared the five test configurations made for each coil. Figure 12 illustrates the quality factor of the transmitter coil $\left(Q_{T x}\right)$ 
and the receiver coil $\left(Q_{R x}\right)$ in addition to their form factor measured in (mm). According to Figure 12a, for the $T_{X}$ coil, the test number 2 gives the best compromise between the quality factor $\left(Q_{T x}\right)$ equal to 46.8 and the form factor of $65.6 \mathrm{~mm}$. For the $R_{X}$ coil, test number 5 gives the best result yielding a quality factor $\left(Q_{R x}\right)$ equal to 95.96 and a form factor of $27.91 \mathrm{~mm}$. Table 7 presents more details about the optimal geometry of the two selected coils configurations based on the simulation results.

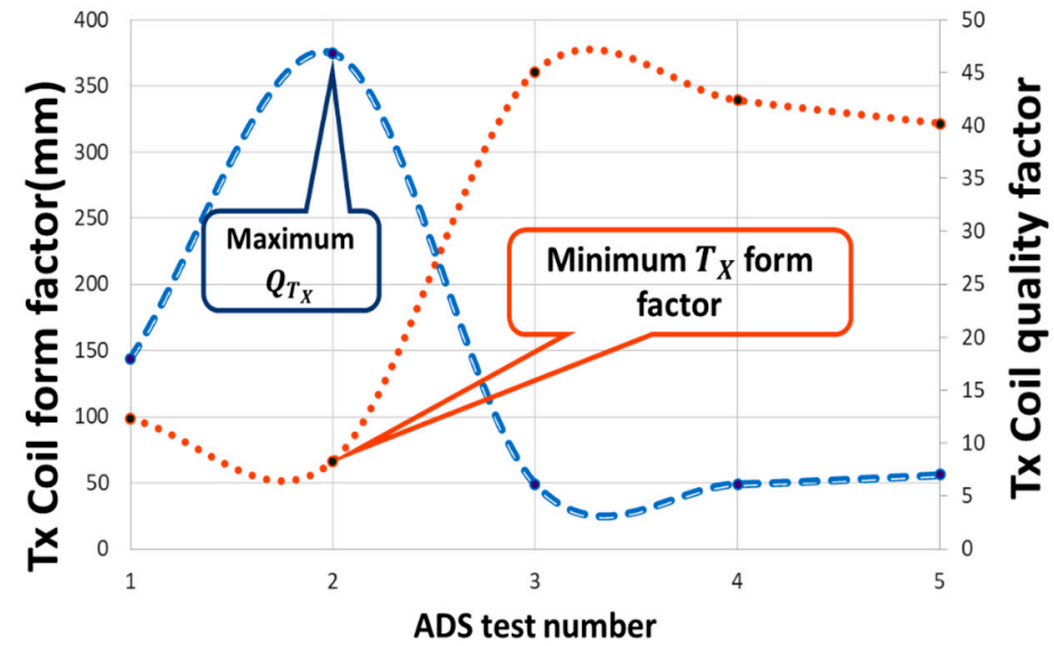

(a)

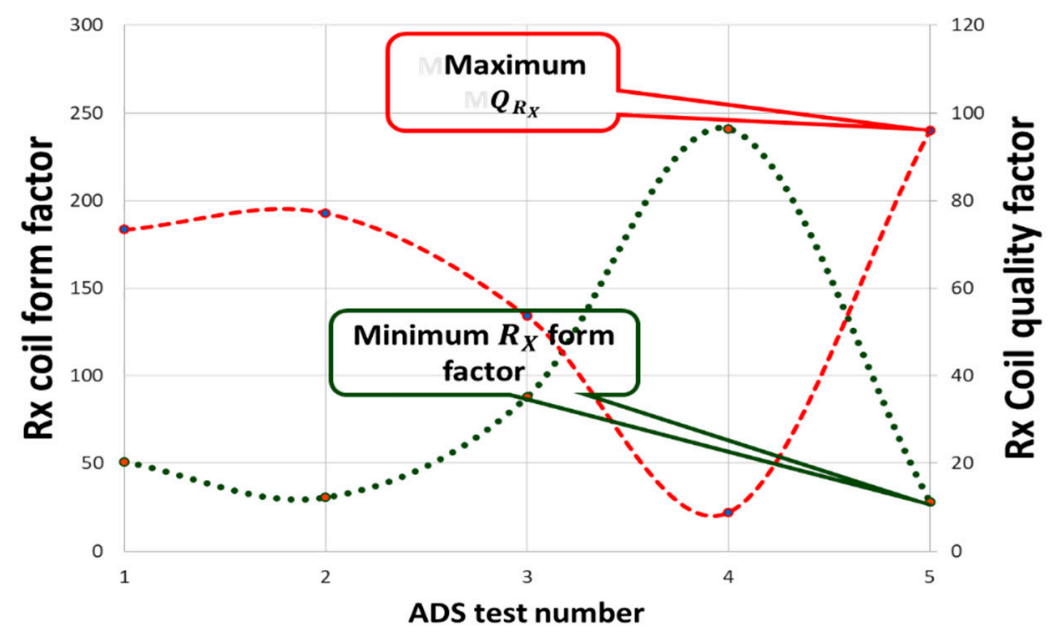

(b)

Figure 12. Coils optimization results using ADS momentum. (a) $T_{X}$ coil; (b) $R_{X}$ coil.

Table 7. Parameters of the optimal geometry of the two coils using ADS momentum.

\begin{tabular}{cccc}
\hline Parameter & $\boldsymbol{T}_{\boldsymbol{X}}$ & $\boldsymbol{R}_{\boldsymbol{X}}$ & Unit \\
\hline N: Number of turns (N) & 18 & 7 & - \\
Ri: Inner radius measured to the center of the conductor & 9.1 & 9.1 & $\mathrm{~mm}$ \\
W: Conductor width & 0.508 & 0.381 & $\mathrm{~mm}$ \\
S: Conductor spacing & 0.8382 & 0.254 & $\mathrm{~mm}$ \\
$L_{n}(\mathrm{H})$ at 13.56 MHz & $5.096 \times 10^{-6}$ & $1.012 \times 10^{-6}$ & $\mathrm{H}$ \\
$R_{S}$ at 13.56 MHz & 9.558 & 0.890 & $\Omega$ \\
Coil size (length = width) & 57.63 & 27.96 & $\mathrm{~mm}$ \\
\hline
\end{tabular}




\section{Testing Methodology and Experimental Results}

In order to confirm the validity of the proposed system, we have conducted the following experiments including and collecting relevant data. First, we have made the DC/AC converter in order to supply the transmitter coil (already explained in Section 2.2). Second, we have made the coils designed with ADS momentum on printed circuit boards using copper as the conductor and the FR4 as a substrate (as already explained in Section 2.3). Finally, we have measured the correlation of the power transmission with the distance between $\left(T_{X}\right)$ and $\left(R_{X}\right)$ coils using an RS PRO digital caliper. During transfer distance measurements, the two coils was perfectly aligned.

Figure 13 presents the block diagram of the proposed near-field RIC WPT system to power-up active implant and Figure 14 is its electrical model made with the Althuim designer software. Firstly, it contains a DC / AC converter producing an efficient power to the primary coil. Secondly, the near-field RIC, which is a serial-parallel resonant topology, is given. This circuit ensures WPT by mutual inductance (M). Table 8 presents parameter values of the system, which result from an accurate calculation. Figure 15 illustrates the experimental measurements of the transferred power as a function of the transfer distance. Figure 16 illustrates the made transmitter and receiver coils.

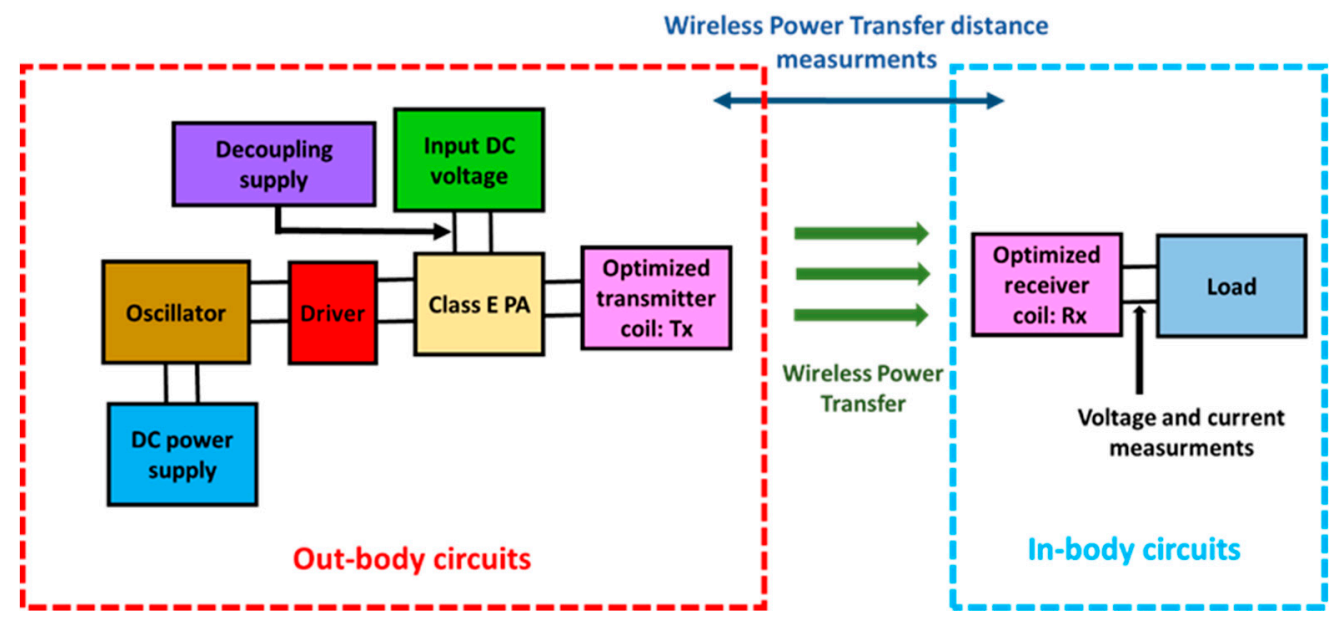

Figure 13. Block diagram of the proposed near-field RIC WPT system.

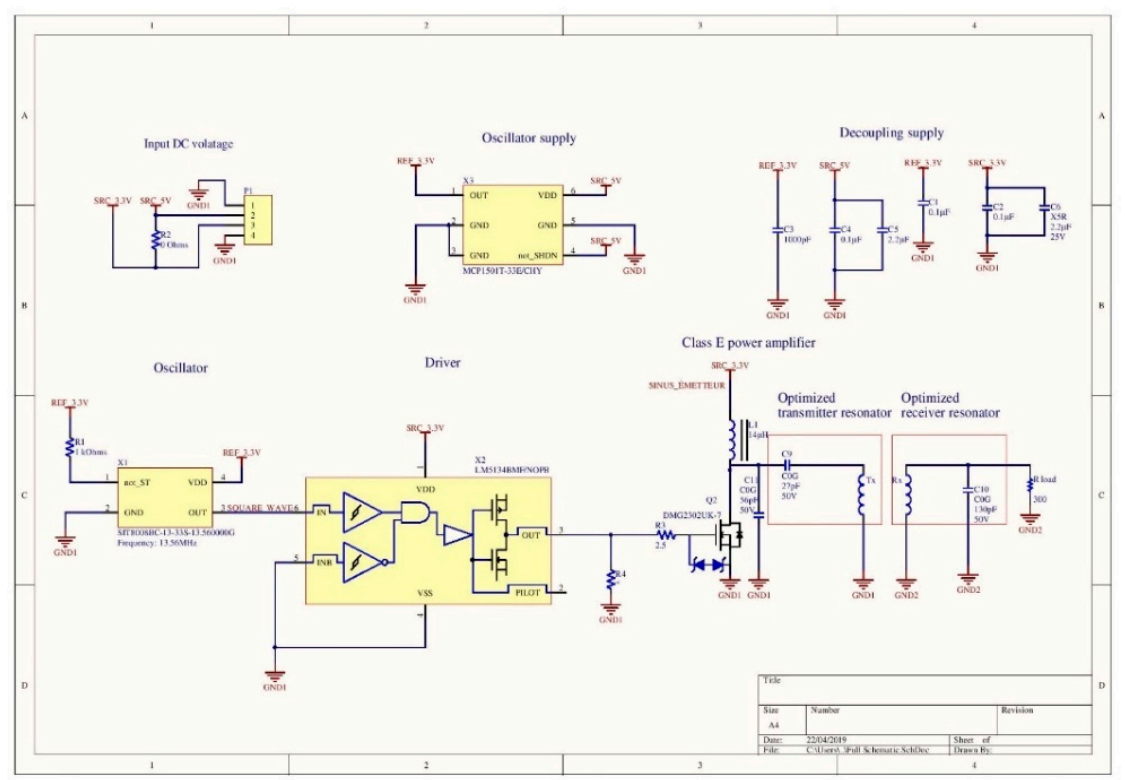

Figure 14. Eclectic design of the proposed near-field RIC WPT system. 
Table 8. System parameters values.

\begin{tabular}{ccc}
\hline Parameters & Values & Unit \\
\hline Supply voltage $($ Vdd) & 3.3 & $(\mathrm{~V})$ \\
Supply voltage of the oscillator & 3.3 & $(\mathrm{~V} / \mathrm{DC})$ \\
Choke inductor $(\mathbf{L} 1)$ & 12 & $(\mu \mathrm{H})$ \\
Shunt capacitor $(\mathbf{C 1 1})$ & 56.5 & $(\mathrm{pF})$ \\
Resonator capacitor $(\mathrm{C} 9)$ & 28 & $(\mathrm{pF})$ \\
Transmitter coil $\left(\boldsymbol{T}_{\boldsymbol{X}}\right)$ & $5.48 \times 10^{-6}$ & $(\mathrm{H})$ \\
Receiver coil $\left(\boldsymbol{R}_{\boldsymbol{X}}\right)$ & $1.0 \times 10^{-6}$ & $(\mathrm{H})$ \\
Resonator capacitor $(\mathbf{C 1 0})$ & 137.75 & $(\mu \mathrm{F})$ \\
Load resistance $\left(\boldsymbol{R}_{\text {Load }}\right)$ & 300 & $(\Omega)$ \\
Frequency & 13.56 & $(\mathrm{MHz})$ \\
Coupling Factor & 0.15 & \\
Duty cycle & 50 & \\
Period & 73.74 & $(\mathrm{~ns})$ \\
\hline
\end{tabular}

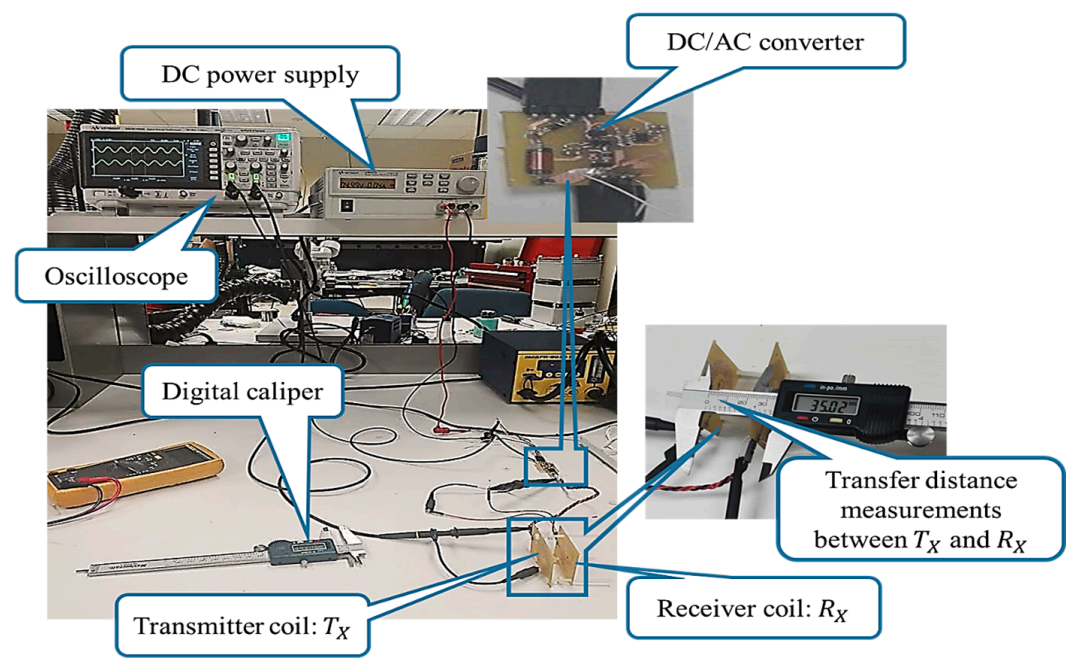

Figure 15. Experimental setup to measure the transferred power as a function of the transfer distance.

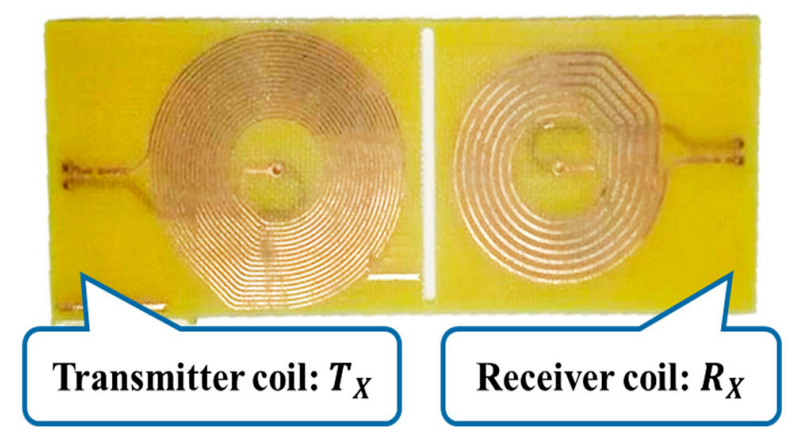

Figure 16. Made transmitter and receiver coil.

\section{Results}

In this section we present our findings related to the DC/AC converter and the power transfer efficiency as a function of the power transfer distance after implementing the proposed design. Figure 17 is the voltage output form of the SiT8008B oscillator at $13.56 \mathrm{MHz}$ generating a single frequency periodic output signal from the DC voltage source. Figure 18 presents the voltage waveform in the transmitter coil $\left(V_{T_{X}}\right)$ which is a perfect sine wave, resulting from the DC/AC converter (oscillator, driver and class E power amplifier). This waveform is an amplified AC voltage of $10 \mathrm{~V} / \mathrm{AC}$ at $13.56 \mathrm{MHz}$. The determined power in the transmitter coil $\left(T_{X}\right)$ is 0.21 Watts. To determine the maximum power transfer efficiency and the maximum power transfer distance that can be reached by the proposed system, we have gradually increased the transfer distance between the two coils. 
During the experiment, we have maintained the transmitter coil fix and we have varied the position of the receiver one. We have started with $0.5 \mathrm{~cm}$ as a first transfer distance and we have increased this distance until a maximum of $5 \mathrm{~cm}$. For each experience, we have measured the transfer distance with a caliper. Figure 19 illustrates the measured voltage waveform in the transmitter coil $\left(V_{T_{X}}\right)$ and the transferred voltage to the receiver coil $\left(V_{R_{X}}\right)$ for a transfer distance equal to $3.5 \mathrm{~cm}$, that are $10 \mathrm{~V} / \mathrm{AC}$ and $5 \mathrm{~V} / \mathrm{AC}$, respectively. Figure 20 shows the received voltage $(\mathrm{V})$ and current $(\mathrm{mA})$ at the receiver coil $(\mathrm{Rx})$ as a function of the transfer distance $(\mathrm{cm})$.

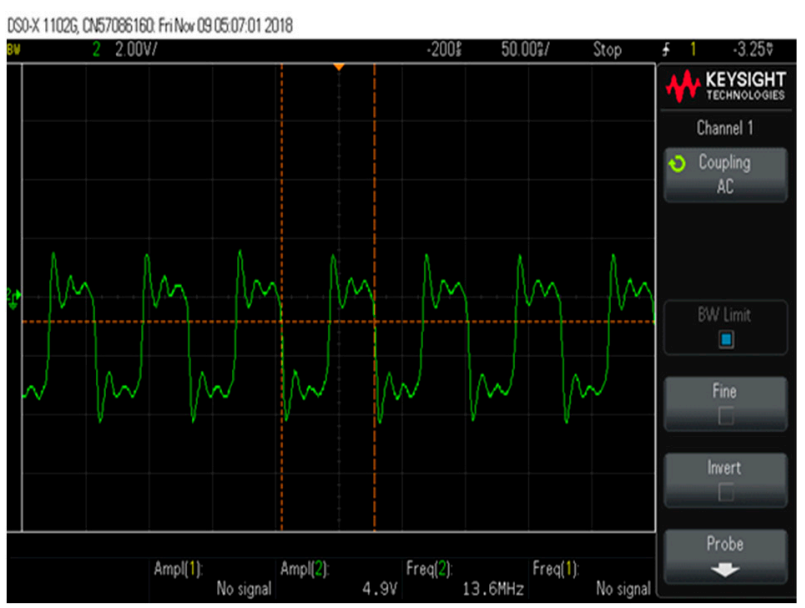

Figure 17. Voltage waveform in the SiT8008B oscillator at $13.56 \mathrm{MHz}$.

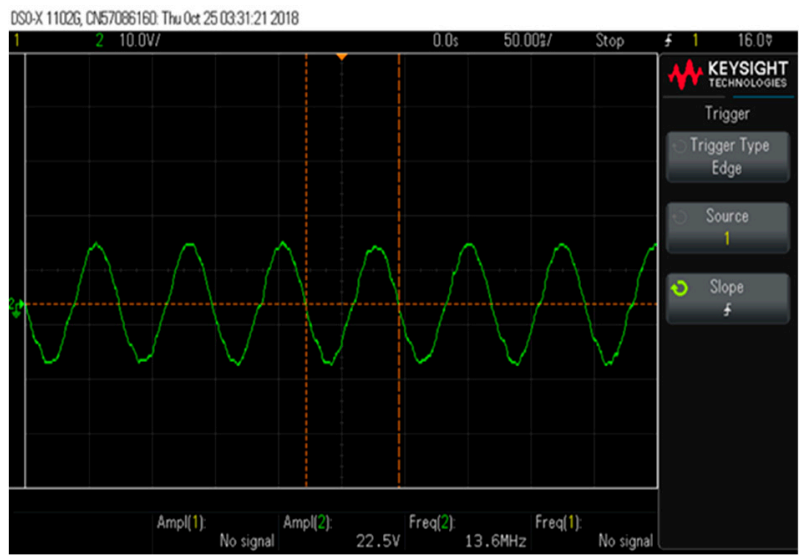

Figure 18. waveform in the transmitter coil $\left(V_{T_{X}}\right)$.

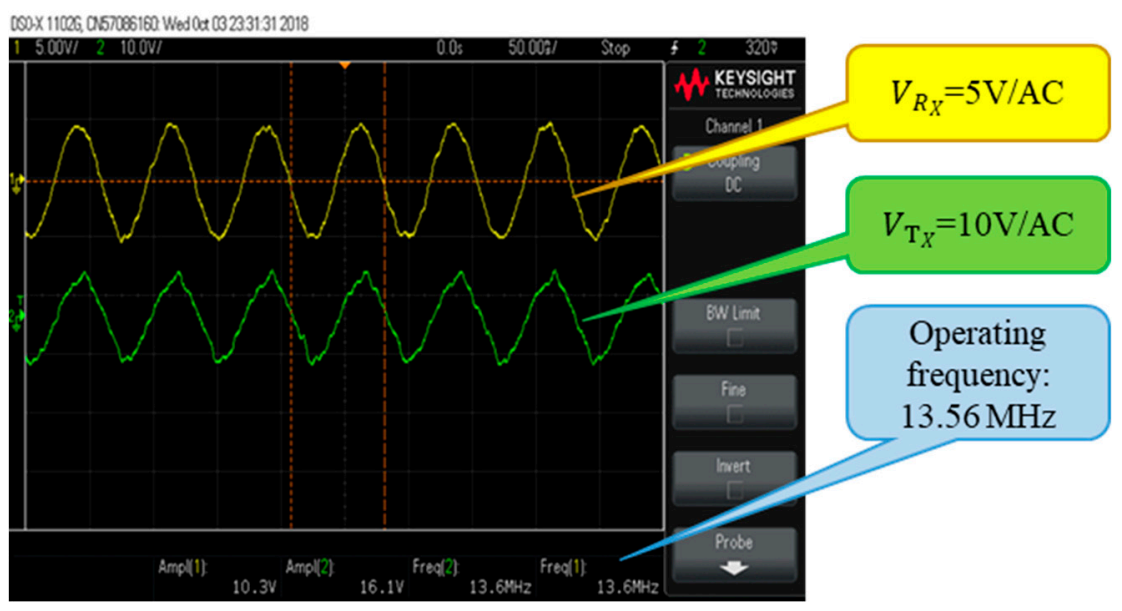

Figure 19. Voltage waveform in the transmitter coil $\left(V_{T_{X}}\right)$ and in the receiver coil $\left(V_{R_{X}}\right)$. 


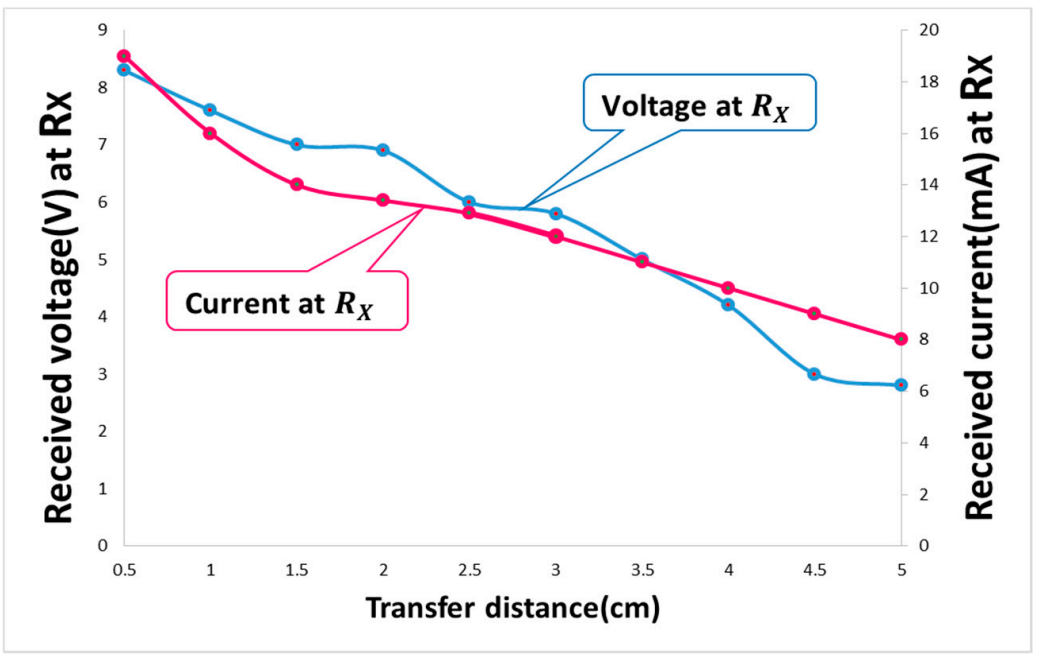

Figure 20. Received voltage $(\mathrm{V})$ and current $(\mathrm{mA})$ at the receiver coil $(\mathrm{Rx})$ as a function of the transfer distance $(\mathrm{cm})$.

\section{Discussion}

Due to the constant increase in the age of the population and social protection against chronic diseases, studies on medical implants are being actively conducted and their market is growing remarkably. Moreover, these devices are increasingly used for conditions such as artificial retinal prostheses or neurostimulators. The energy requirements of most implants range from a few microwatts to tens of milliwatts and this generally depends on their specific applications. Whenever they are active, they require an electrical power source to operate correctly. Nevertheless, the short lifetimes of batteries that supply these devices are the major disadvantage of their good use because of the surgical operations necessary to replace them. According to the literature, there are ubiquitous attempts and proposals for powering implants. However, not all the proposed techniques can satisfy modern implant design requirements (human body safety, size, produced power, etc.). Near-field WPT using resonant inductive coupling (RIC) seems the best solution for transcutaneous applications.

WPT in RIC is ensured by the magnetic induction phenomenon. When the transmitter coil generates a magnetic field, the receiver coil receives this magnetic field and induces an electrical power current. As the magnetic coupling between the two coils is high the power transfer efficiency is important. However, the weakness of the inductive coupling efficiency is usually the bottleneck in the overall WPT system efficiency. That makes the power transfer efficiency the most important parameter to be considered during the system design. Improving this parameter, increases the human safety and reduces the system form factor.

In this paper, we have looked for a way to satisfy the power needs of implanted medical devices without the need for batteries. For this reason, we have investigated a novel design for WPT using a high-efficiency Complementary Metal Oxide-Semiconductor (CMOS) and an optimized Printed Circuit Coil (PCC). The system operates at $13.56 \mathrm{MHz}$. It is divided into two main circuits, a transmitter circuit located outside the human body and a receiver circuit implanted inside the body. The transmitter circuit contains an oscillator, driver and a Class-E power amplifier and it has been designed with the software Althuim designer 2017. Transmitter (Tx) and receiver (Rx) coils have been optimized using the ADS momentum 2015 software.

Figure 21 illustrates the system power transfer efficiency and the received voltage in the receiver coil $\left(R_{X}\right)$ versus the transfer distance measured during the experiments. The maximum power transfer efficiency reaches by our system is $75.1 \%$ for a $0.5 \mathrm{~cm}$ (the measured voltage is $8.2 \mathrm{~V}$ and the current is $19 \mathrm{~mA}$ ). This efficiency decreases to $10.67 \%$ with the transfer distance for $5 \mathrm{~cm}$ (the measured voltage is $2.8 \mathrm{~V}$ and the current is $8 \mathrm{~mA})$. The received power in the receiver coil $\left(R_{X}\right)$ for the distances $0.5 \mathrm{~cm}$ and $5 \mathrm{~cm}$ are $157.7 \mathrm{mWatts}$ and $22.4 \mathrm{mWatts}$, respectively. These results are very useful and promising, 
especially knowing that implants are devices with a low power consumption. In most cases, the power requirements of active implants range from a few microwatts to tens of milliwatts. Moreover, the skin depth in the human body is about $0.6 \mathrm{~mm}$.

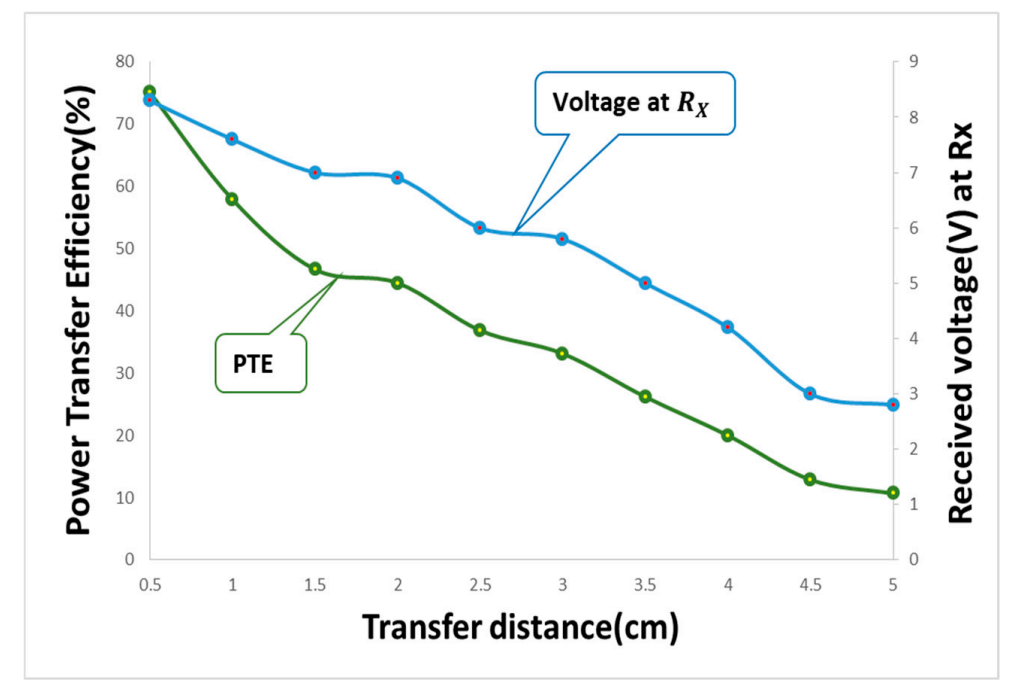

Figure 21. Power transfer efficiency (\%) between the two coils and the received voltage (V) in the receiver coil $\left(R_{X}\right)$ as a function of the transfer distance $(\mathrm{cm})$.

Table 9 illustrates a comparison between our result and other studies based on the transferring distance and the wireless transfer efficiency between the transmitter and the receiver circuits. All the presented works have used the RIC technique to design WPT systems for medical implants. The system proposed in [33] ensures a high power transfer distance and efficiency compared with our work, but it operates at a low frequency. Low frequency magnetic waves have a low absorption rate in the human body, which causes a rise of the skin temperature and limits their application. The system proposed in [34] operates at $27 \mathrm{MHz}$, for high frequency bands. If the rate increases, the transmitted power increases, but the tissue warming effects become severe. This system reaches a transfer distance greater than our system but gives a low transfer efficiency between the two circuits. Systems proposed in [35] and [36] operate at the same frequency of our system, but our system achieves the highest transfer distance $(0.5 \mathrm{~cm})$ and the highest transfer efficiency $(75.1 \%)$. Finally, the work presented in [37] has a lower efficiency than the proposed system. These results confirm the reliability and the utility of our proposed system for transcutaneous applications that use low power consumption devices. Moreover, the result of this work can be used as a model for WPT for transcutaneous applications that need a short transfer range.

Table 9. Comparison between the previous literature and this work.

\begin{tabular}{|c|c|c|c|c|}
\hline Previous literature & Used Approach & $\begin{array}{c}\text { Transfer } \\
\text { Distance }(\mathrm{cm})\end{array}$ & $\begin{array}{l}\text { Power Transfer } \\
\text { Efficiency (\%) }\end{array}$ & Frequency \\
\hline [33] & \multirow{6}{*}{ RIC } & 1 & 86 & $742 \mathrm{kHz}$ \\
\hline [34] & & 5 & 11.3 & $27 \mathrm{MHz}$ \\
\hline [35] & & 3 & 21.7 & $13.56 \mathrm{MHz}$ \\
\hline [36] & & 1 & 58 & $13.56 \mathrm{MHz}$ \\
\hline [37] & & 1 & 41.62 & Not available \\
\hline This work & & 0.5 & 75 & $13.56 \mathrm{MHz}$ \\
\hline
\end{tabular}

While investigating coil geometries, we have found that current technology fabrication constraints limit our ability to decrease the form factor of the coils and increase their efficiency (reduce their parasitic resistance). Moreover, system implementation has been done in an air medium without 
considering the human body and the EMF safety (specific absorption rate or SAR, human body exposure limits to EM fields, etc.). As a first follow-up, we plan to investigate the coil geometry with another technology, namely the low temperature co-fired ceramics (LTCC) to meet these challenges. This technology offers the possibility to make coils with different materials (silver, gold, etc.), and substrates (Ferro L8, ceramic, etc.) that may provide a compromise between a small coil size or form factor and a high efficiency. Another perspective of this work, is to consider the different human body media (fat, skin, etc.) during system design. The maximum distance obtained in this work is $5 \mathrm{~cm}$ in the air medium which is different from what would be possible in biological material due to the permeability of the medium, especially for deep implants.

Author Contributions: All authors contributed equally in this work.

Funding: This research has been funded in part by Canada Research Chair in Energy Conversion and Power Electronics CRC-ECPE, École de Technologie Supérieure, Montréal.

Acknowledgments: This project was funded in part by the Deanship of Scientific Research (DSR) at King Abdulaziz University, Jeddah, under grant no. KEP-2-135-39. The authors, therefore, acknowledge with thanks DSR for technical and financial support. for its administrative and technical supports.

Conflicts of Interest: The authors declare no conflict of interest.

\section{References}

1. Valentinuzzi, M. Cardiac pacemakers. IEEE Pulse, 14 July 2017; $1-4$.

2. Kiourti, A.; Konstantina, S.N. A review of In-body Biotelemetry Devices: Implantable, Ingestible, and Injectable. IEEE Trans. Biomed. Eng. 2017, 464, 1422-1430. [CrossRef]

3. Rieger, B.; Pfau, S.; Stieglitz, J.; Asplund, T.; Ordonez, S.J. Concept and Development of an Electronic Framework Intended for Electrode and Surrounding Environment Characterization in Vivo. Sensors 2017, 17, 59. [CrossRef]

4. Andreozzi, E.; Gorgiulo, D.; Fratini, G.; Esposito, A.; Bifulco, P. A Contactless Sensor for Pacemaker Pulse Detection: Design Hints and Performance Assessment. Sensors 2018, 18, 2715. [CrossRef]

5. Trigui, A.; Hached, S.; Chiheb, A.; Savaria, Y.; Sawan, M. Maximizing data transmission rate for implantable devices over a single inductive link: Methodological review. IEEE Rev. Biomed. Eng. 2018, 12, 72-87. [CrossRef]

6. Khokle, P.; Essello, K.; Bokor, D. Design, Modeling, and Evaluation of the Eddy Current Sensor Deeply Implanted in the Human Body. Sensors 2018, 18, 3888. [CrossRef]

7. Amor, A.B.; Kouki, A.B.; Coo, H. Power approaches for implantable Medical devices. Sensors 2015, 15, 28804-28890. [CrossRef] [PubMed]

8. Ben Fadhel, Y.; Ktata, S.; Rahmani, S.; Al-Haddad, K. General Principle of Wireless Power Transmission and Its Applications in Medical Devices; EICON: Florence, Italy, 2016; pp. 3-5.

9. Mohamad, J.A.; Nordin, R.; Kamel Ghaghan, S.; Mahmoud Jawad, H.; Ismail, M. Opportunities and challenges for Near-Field wireless transfer: A review. Energies 2017, 10, 1022.

10. Jow, U.-M.; Ghovanloo, M. Design and optimization of printed spiral coils for efficient transcutaneous inductive power transmission. IEEE Trans. Biomed. Circuits Syst. 2007, 1, 193-202. [CrossRef] [PubMed]

11. Poon, S.Y.; O'Driscoll, S.; Meng, H.T. Optimal frequency for wireless power transmission into dispersive tissue. IEEE Trans. Antennas Propag. 2010, 58, 1739-1750. [CrossRef]

12. Ram Rakhyani, A.K.; Mirabbasi, S.; Chiao, M. Design and optimization of resonance-based efficient wireless power delivery systems for biomedical implants. IEEE Trans. Biomed. Circuits Syst. 2011, 5, 48-63. [CrossRef]

13. Jolani, F.; Mehta, J.; Yu, Y.; Chen, Z. Design of wireless power transfer system using magnetic resonance coupling for implantable medical devices. Progress in electromagnetic. Res. Lett. 2013, 40, 141-151.

14. Campi, T.; Cruciani, S.; De Santis, V.; Palandrani, F.; Hirata, A.; Feliziani, M. Wireless power transfer charging system for AIMDs and pacemakers. IEEE Trans. Microw. Theory Tech. 2016, 64, 633-642. [CrossRef]

15. Trigui, A.; Hached, S.; Mounaim, F.; Ammari, A.C.; Sawan, M. Inductive power transfer system with self-calibrated primary frequency. IEEE Trans. Power Electron. 2015, 30, 6078-6087. [CrossRef]

16. Kiani, M.; Jow, U.; Ghovanloo, M. Design and optimization of a 3-coil inductive link for efficient wireless power transmission. IEEE Trans. Biomed. Circuits Syst. 2011, 5, 580-591. [CrossRef] [PubMed] 
17. Kiani, M.; Lee, B.; Xeon, P.; Ghovanloo, M. A Q-modulation technique for efficient inductive power. IEEE Solid State Circuits 2016, 50, 2839-2848. [CrossRef] [PubMed]

18. Ben Fadhel, Y.; Ktata, S.; Rahmani, S.; Al-Haddad, K. Used Methods to wirelessly powered Implantable Medical Devices. In Proceedings of the 17th International Conference on Sciences and Techniques of Automatics \& Computer Engineering (STA 2016) Sousse, Tunisia, 19 December 2016; pp. 2-4.

19. Jegadeesan, R.; Agarwal, K.; Guo, Y.; Yen, S.; Thakor, N. Wireless Power delivery to the flexible subcutaneous implant using capacitive coupling. IEEE Trans. Microw. Theory Tech. 2017, 65, 280-292. [CrossRef]

20. International Commission on Non-Ionizing Radiation Protection. Guidelines for limiting exposure to time-varying electric and magnetic fields for low frequencies $(1 \mathrm{~Hz}-100 \mathrm{KHz})$. Health Phys. 2010, 99, 818-836.

21. IEEE Standard for Safety Levels with Respect to Human Exposure to Radio Frequency Electromagnetic Fields, $3 \mathrm{KHz}$ to $300 \mathrm{GHz}$; IEEE Standard C95.1; IEEE: Piscataway, PA, USA, 2005.

22. Jiang, J.; Chau, K.T.; Liu, C.; Lee, H.T.C. An overview of resonant circuits for wireless power transfer. Energies 2017, 10, 894. [CrossRef]

23. Houran, A.M.; Yang, X.; Chen, W. Magnetically Coupled Resonance WPT: Review of Compensation Topologies, Resonator Structures with Misalignment, and EMI Diagnostics. Electronics 2018, 11, 22. [CrossRef]

24. Jamel, N.; Yasmarnita, Y.S.; Isa, T.Z.M.S.; Isa, A.A.M. Investigation on capacitor compensation topologies effects of different inductive coupling links configurations. IJPEDS 2014, 6, 274. [CrossRef]

25. Rehman, M.; Baharudin, Z.; Nallagownden, P.; Islam, U.B.; Ur Rehman, M.Z. Modeling and analysis of series-series and series-parallel combined topology for wireless power transfer using Multiple coupling coefficients. IJCSNS 2017, 17, 114-123.

26. Nutwong, S.; Sangswong, A.; Naetilddanon, S.; Mujjalinvimut, E. Output voltage of control of the SP topology control IPT system based on operating side controller operating at ZVS. ECTI Trans. Comp. Inf. Technol. 2017, 11, 71.

27. Jeng, Y.G.; Hung, Y.; Huang, Y.; Lee, T.; Tai-Haur, K. A Wireless Power Transfer System with Reconfigurable Series/Parallel (RSP) Receiver; Automotive Research and Testing Center (ARTC): Lukang, Taiwan, 2015.

28. Cui, S.; Liu, Z.Z.; Jhou, Y.; Zing, H.; Yue, Z.K.; Hiang, H.L. Study on efficiency of different topologies of magnetic coupled resonant wireless charging. In Proceedings of the Earth and Environmental Science Conference, Kunming, China, 22-25 September 2017.

29. Liu, L.; Lin, B.; Zhu, X. Optimization of Rotary Transformer for RUM with Secondary Self-Compensation; Elsevier: Amsterdam, The Netherlands, 2018; p. 740.

30. Chen, K.; Peroulis, D. Desing of highly efficient broad class-E power amplifier using synthesized low-pass matching networks. IEEE Trans. Microw. Theory Tech. 2011, 59, 3163-3165. [CrossRef]

31. Agrwal, K.; Deesan, J.R.; Guo, Y.-X.; Thakor, V.N. Wireless power transfer strategies for implantable bioelectronics: Methodological review. IEEE Rev. Biomed. Eng. 2017, 10, 136-161. [CrossRef] [PubMed]

32. Mehri, S.; Ben Haj Slama, J.; Ammari, A.C.; Rmili, H. Genetic algorithm based geometry optimization of inductively coupled spiral coils for remote powering of electronic implantable devices. J. Sens. 2016, 2016, 4869571. [CrossRef]

33. Li, X.; Zhang, H.; Peng, F.; Li, X.; Wang, B. A Wireless Magnetic Resonance Energy Transfer System for Micro Implantable Medical Sensors. Sensors 2012, 12, 10293-10308. [CrossRef] [PubMed]

34. Rajagoplan, A.; Ramrkhyani, A.; Schiurig, D.; Lazzi, G. Improving Power Transfer Efficiency of a Short-Range Telemetry System Using Compact Metamaterials. IEEE Trans. Microw. Theory Tech. 2014, 62, 947-955. [CrossRef]

35. Kilin, E.G.; Ghanad, A.; Maloberti, F.; Dehollain, C. A RemotelyPoweredImplantableBiomedicalSystem with Location. IEEE Trans. Biomed. Circuit Syst. 2015, 9, 113-123.

36. Xue, R.; Cheng, K.; Je, M. High efficiency wireless power transfer for biomedical implants by optimal resonant load transformation. IEEE Trans. Circuits Syst. 2012, 60, 867-874. [CrossRef]

37. Niroomand, M.; Lotifian, M. A wireless power transmission to supply deep brain stimulators. Biomed. Res. 2015, 26, 497-504.

(C) 2019 by the authors. Licensee MDPI, Basel, Switzerland. This article is an open access article distributed under the terms and conditions of the Creative Commons Attribution (CC BY) license (http:/ / creativecommons.org/licenses/by/4.0/). 